\title{
Exploration of Industry-education Integration Co-building Practice Base in Higher Normal Music Colleges
}

\author{
Hao Tian \\ China West Normal University, Nanchong Sichuan, 637002, China
}

Keywords: industry-education integration; higher normal music college; practice base

\begin{abstract}
Education practice as an important component in the teaching system of higher normal music colleges has irreplaceable value for teachers and students to consolidate their professional knowledge, improve their practical teaching skills and related work abilities. The practice base is an essential internship platform for higher normal music colleges. The effectiveness of its construction will greatly affect the practice effectiveness of high normal college teachers and students. Industry-education integration co-building practice base in higher normal music colleges which can greatly enhance students' practical learning effect is worthy of promotion and application. On the basis of summarizing industry-education integration, this paper has elaborated the necessity of industry-education integration co-building practice base in higher normal music colleges, and listed the basic goals, requirements, and main contents, and analyzed the effect of industry-education integration co-building practice base in higher normal music colleges.
\end{abstract}

\section{Introduction}

In December 2017, "Several Opinions of the State Council on Deepening Industry Education Integration” by the General Office of the State Council, which clarified that the main goal of industry-education integration in China is to continuously improve the participation of industrial enterprises in running schools, improve the diversified school running mechanism, and implement school-enterprise cooperative talent cultivation, and spend about 10 years to realize industry-education integration, establish a benign development pattern, and promote the proper resolution of structural contradictions between the high-level personnel supply and industrial needs. Vocational education and higher education has significantly contributed more to social and economic development. The practice base construction is an extremely important part of the education in higher normal music colleges, as well as an important step for students to transform their role to professionals. Industry-education integration co-building practice base in higher normal music colleges can help to fulfill the mission of promoting the students' development and becoming elites.

\section{Summary of industry-education integration}

Industry-education mainly refers to higher professional colleges and universities closely link industry with education and teaching based on their own specialty practice through mutual support and promotion to make the become a market operation subject integrating talent cultivation, scientific research management, and technology services, and to establish a new school-running model for both vocational colleges and businesses. The goal of industry-education integration is to cultivate practical and high-level talents. Although production is the basis, it must be subordinate and serving teaching practice. This is the principle of properly handling related issues during industry-education integration. In the current situation, it should be deepened based on integration, which will determine the overall level of industry-education integration in China.

\section{The necessity of industry-education integration co-building practice base}

Industry-education integration co-building practice base can adapt to the needs of the society and 
the market. Higher normal colleges can cultivate professional talents purposefully according to the feedbacks and needs of employers. We must combine the current market development trends and focus on improving the practical skills of students in higher education so as to better cultivate the talents needed by society. Meanwhile, industry-education can achieve "win-win" and realize information sharing and resource sharing between higher normal colleges and industry entities. Higher normal teachers can use the practical training facilities provided by the industrial entity, and industry subjects no longer worry about the problems of teaching field needed to train high-quality talents, so that students can be close connected between school learning and practice base training, which can reduce the cost of both parties. As a brand-new exploration, this topic is related to the higher normal students, higher normal colleges, and companies. In the research, we may encounter various kinds of complicated problems. For example, in the process of industry-education integration, there exist a conceptual difference in understanding cooperation between the two parties; the mutual recognition of mutual credits is difficult. In order to promote industry-education integration co-building practice base in higher normal music colleges, it is necessary to carry out researches on higher normal students' practice psychology from the aspects of higher normal students, higher normal colleges, and industry subjects, and delicately explore industry-education integration schemes, perfect the cultivation goal of higher normal music talents so as to clarify the standard of industry-education integration co-building practice base in higher normal music colleges.

\section{Basic objective of industry-education integration co-building practice base in higher normal music colleges}

Basic objective of industry-education integration co-building practice base in higher normal music colleges can be set according to the higher normal music talent training program and music specialty course standard. To ensure healthy operation of the practice base, a relevant number of integrated and open training sites should be designed to guarantee time and funding, and to further promote the professional development of the training room talents and build more professional high-quality talent teams. By doing so, we can build comprehensive practical training base which can provide full-service and guide the better development of music-related subjects. We need to promote the integrated development process of industry-education-research integration, promote to establish a school-government-enterprise cooperation system, and vigorously implement training work. Meanwhile, it is necessary to establish an assessment system for industry-education integration practice bases, incorporate the content of practical teaching into the school's teaching system, specify class hours and credits, and set detailed time and task requirements for students' participation in practice base learning. The teacher's participation in the higher normal students' practice learning should be included in the teaching amount. Carry out related subject exploration by using subordinate training labs and establish teaching research teams. It is also necessary to set up music practice creative talent team so as to create high-quality, innovative musical works or musical programs, and actively participate in national, provincial, and municipal competitions for the purpose of better manifesting the culture inheritance and innovative educational function of practice base.

\section{Basic requirements of industry-education integration co-building practice base in higher normal music colleges}

Industry-education integration can be categorized into two major types: on-campus and off-campus. However, a team of qualified teaching personnel with a very reasonable structure including professors, associate professors and other professional talents, musicians, and non-genetic inheritors should be equipped in reach type. The ratio of teachers should be scientific, standardized and reasonable. When building school's practice base, various hardware facilities for carrying out normal practice teaching activities, such as piano rooms, piano rooms, dance studios, computer music rooms, and studios should be set so as to provide adequate education for students of related majors such as music, arts, and pre-school education to conduct practical learning. When building 
off-campus practice base, it is necessary to provide practice sites of practice, teaching, art services, and other aspects for higher normal music students so as to provide guarantee for fully implementing practice learning. During industry-education integration co-building practice base in higher normal music colleges, music education system with local music characteristics should be established to implement practice education and teaching, and to strengthen the practical ability and creativity of higher normal music major students, and strengthen music practice-oriented professional base construction, vigorously promote education and teaching reform, and strive to improve education quality. Teaching content should be regarded as the core content of professional development, to enrich and update the specific education and teaching contents. The latest research results of music specialty should be introduced into the teaching process, so as to constantly improve the normalization and scientificity of education contents. By strengthening the assessment of the practice curriculum in higher normal colleges, keep improving the assessment mechanism and the overall quality of students in higher normal colleges, thus building a better practice platform for cultivating utility-type music professional talents.

\section{Main contents of industry-education integration co-building practice base in higher normal music colleges}

Firstly, create an efficient, scientific, and standardized practice base management mechanism, continue to perfect rules and regulations for practical training bases, promote standardization and scientization of practical teaching, and continuously improve the effectiveness of teaching in practice bases. It is necessary to constantly improve a series of rules and regulations such as the training room management system, practical training instructors' teaching norms, students' practical training operation procedures, practice base equipment management system, training room use system, practice base safety management system, create practical teaching log, practical documents such as practice management methods, practical teaching effectiveness evaluation systems, and practical instructors' work evaluation systems. Secondly, rapidly adjust the training program for music professional talents according to students' problems in the practice base to perfect practical music talent training, and use the advantages of the school's internal and external practice bases to create benign interactive cooperative system under the development of professionals, folk artists and professional teachers jointly. Organize practical teaching mechanisms based on the work process, comprehensively carry out specific job analysis, and apply all kinds of social resources to carry out different forms of practical teaching. Thirdly, fully promote the work of practice education. Clarify various targets of practical teaching, select the specific content of practical teaching according to the requirements of the job task, knowledge and skills, and integrate the learning content selected by the students and teachers through proceduring professional activities. Select scientific practical teaching methods, including student ability assessment into key areas, and formulating practical teaching plans and practical training teaching outlines for music major students in form of industry subjects and experts' scoring by means of scientific practical methods through industry-education integration, so as to better meet the needs of education and training, and perfect practice hardware facilities and equipment. The author believes that the music-related equipment in the practice base should reach a level at least medium above. Meanwhile, cooperate with the industry subjects to establish a professional qualification certification system. Fourthly, improve the dual-teacher type professional training teacher team. The teaching staff in the practice base should be the backbones and the leaders of music teaching and research in local universities. Also, we must actively introduce folk art talents, excellent musicians, and other full-time or part-time instructors. At the same time, teachers in practical bases should be given priority to be sent to music companies and institutions to learn new skills, so as to lay a good foundation for nurturing the reserves of music subject. Fifthly, focus on social services. Industry-education practice base in higher normal music colleges is not only a practice venue for music major students, but also an important base for the cooperative industry subjects. Construction of practice base should be based on the principle of complementary advantages and resource sharing, and give full play to advantages such as talents, culture, and 
information in normal colleges. Promote professional talent development, teaching research, and achievement conversion in relevant companies based on the implementation of practical teaching, so as to promote better development of practice bases and help higher normal college teachers and students to better benefit the society in the future.

\section{Effect analysis of industry-education integration co-building practice base in higher normal music colleges}

Substantial effect has been achieved through industry-education integration co-building practice base in higher normal music colleges, mainly in the following three aspects: Firstly, from the perspective of normal colleges, industry-education integration co-building practice base in higher normal music colleges is suitable for the rules of higher education development, and it can promote the development of regular higher normal music colleges. Higher normal colleges can greatly improve education quality, strengthen the cooperation between market players when cooperating with industry subjects so as to achieve a "win-win" relationship between the two sides. In the process of industry integration, both parties can also gradually deepen their cooperation, broaden the scope of mutual cooperation, carry out research and development of characteristic projects, reform and optimize current methods of higher normal college student cultivation, so as to further promote the reform process of higher normal music colleges. Secondly, from the point of view of the industry subject, industry-education integration co-building practice base in higher normal music colleges is in line with the needs of modern enterprises and institutions in talent cultivation, so as to implement the personnel training strategy. After obtaining corresponding benefits, the industry subject can strengthen their initiative of participating in industry integration and talent cultivation. Students in higher normal colleges can benefit under the guidance of professionals in practice base, and they can also improve their quality. Based on industry integration, relevant enterprise concepts and culture can be imparted to teachers and students, so as to cultivate more practical music talents for the society. Thirdly, from the perspective of students in higher normal colleges, it is in line with the needs of higher normal college students' career development and it can greatly enhance their ability so as to improve students' entrepreneurship and improve their employment competitive strength, which connect graduation with employment. Based on the industry integration, teachers and students can establish a good sense of career development. Through practical learning, they can have a certain practical ability. Meanwhile, the exercise in the practice base will help to improve students' sense of organizational discipline, good professional ethics, meticulous working attitude, and sincere cooperation and team awareness. It can also lays a good foundation for students' future career planning.

\section{Conclusion}

In conclusion, industry-education integration co-building practice base in higher normal music colleges can directly affect the quality and effectiveness of higher normal students' practice learning just like only rich soils can produce fruitful results. Developing practice learning is a very important opportunity for higher normal college students to experience practical teaching. Therefore, building high-level practice base through industry-education integration is be obligatory on higher normal music colleges. Building high-quality industry-education integration practice base will allow music major students to experience a comprehensive education and teaching process. They can also fully participate in the music teaching, stage practice, and the mass literature and art, and innovative subject research. By doing so, the practice base can display its characteristics, and higher normal college students can find the development direction most suitable for their own employment after experiencing the practice base, so as to lay a solid foundation for their future employment. 


\section{Acknowledgement}

This research was financially supported by the Construction and practice exploration of “industry-education integration” talent training mode in higher normal music colleges.

\section{References}

[1] Dong Yuqi, Hou Nu. Field study on education practice, Northeast Normal University Press, 2009.

[2] Ma Chengrong. Studies on school-enterprise cooperative mode, Education and Career, 2007(23).

[3] Gao Jie, Song Xinjuan. Studies on music major students' capability evaluation index characteristics in local comprehensive universities, Theory Monthly, 2014(5).

[4] Yang Yuxing. Current situation of practice base building in higher vocational college and development countermeasures, Computer Knowledge and Technology, 2014(15).

[5] Li Yongyun. School-running thoughts on music applied professional talent training, Journal of Chuxiong Normal University, 2015(5). 